\title{
Study on Education Reform of Principle and Application of Microcontroller Based on C8051F Family
}

\author{
Sheng-ju SANG, Fang LI and De-yun YANG \\ School of Information Science and Technology \\ Taishan University \\ Taian Shandong, China, 271000 \\ sang1108@163.com
}

\author{
Yue-ying WU \\ School of Mathematics and Statistics \\ Taishan University \\ Taian Shandong, China, 271000 \\ wyy7758525@126.com
}

\author{
Yue-ying WU \\ School of Information Science and Technology \\ Qingdao University of Science and Technology \\ Qingdao, Shandong, China, 266061 \\ Corresponding author:wyy7758525@126.com
}

\begin{abstract}
This paper reformed the teaching content of the course of the principle and application of single chip microcomputer in view of the current situation of the teaching and application. Different students, with different characteristics, interest, specialties, have different teaching and experiment contents, according to the application of microcontroller based on C8051F Series MCU, which is a new generation of SOC. A novel quantitative evaluation for students' learning achievement was also produced combined with the actual situation, quantitative assessment, comprehensive evaluation, etc. The teaching and experiment content have been advanced and practical, and good results obtained. It improved the students' interest in learning and achieves better results.
\end{abstract}

Keywords - C8051; single chip Microcomputer; education reform; quantitative evaluation

\section{INTRODUCTION}

Since 1970s, the single-chip microcomputer has developed from 4-bit to 8-bit, and has developed rapidly from 16-bit to 32-bit, which was regard as a new type of high single chip computers [1]. Nowadays, it has become a unique branch of computer technology. With the continued growth of the development of manufacturing technology and market demand in recent years, the development speed of the embedded controller is amazing. Embedded micro controller has integrated traditional computers technology together with many new design ideas, such as Harvard architecture, system on chip (SOC), in system programming (ISP), pipelining technology, caching technology and so on [2]. Compared with the high-end one of massive microcontroller families, the traditional 51 core serial microcontroller seems to be out of date. In fact, organically combined a large number of traditional 51 MCUs software and hardware resources, engineer development experience with some of the new technology, the original software and hardware resources can be utilized effectively, and the project developers porting task can reduced also[3-4].

In this paper, $\mathrm{C} 8051 \mathrm{~F}$ is adopted in application, which is a new type of successful MCU in recent years; strictly speaking, it is not the traditional sense of the "single", but within system programming (ISP) and system on chip (SOC) technology.

\section{C8051F FAMILY}

C8051F MCU families are produced by Silicon Labs company, keeping the performance and the integration with the smallest micro controller package (as small as $2 \mathrm{~mm}$ x $2 \mathrm{~mm}$ ). The C8051F MCUs are fully integrated mixed-signal System on a Chip MCUs with an internal programmable oscillator $( \pm 2 \%)$, a true 12-bit multi-channel ADC, a true 12-bit multi-channel ADC, a voltage reference, 100MIPS throughput with $25 \mathrm{MHz}$ clock, Built-in temperature Sensor $\left( \pm 2^{\circ} \mathrm{C}\right)$ and an 8051 -compatible MCU core with 32kbytes of FLASH memory. There are also I2C/ SPI bus, UART, and SPI serial interfaces implemented in hardware as well as a Programmable Counter/Timer Array (PCA) with five capture/compare modules. There are also 4 general-purpose 16-bit timers and 4 byte-wide general-purpose digital Port I/O [5-6]. The C8051 is a 'hard wired' implementation of the 8051 microcontroller CPU, as opposed to the original micro-coded version. The instruction set is mapped to a basic two-stage pipeline to increase throughput while maintaining an 8-bit program memory width. The result is a high-performance 8051 microcontroller architecture that executes most instructions within 1 or 2 clock cycles and delivers 20 to 25 times the performance of the original 8051 core [7-8]. 
The emergence of C8051F MCUs makes the industry refreshing, so that the majority of MCU system designers saw a new dawn of 51 single-chip microcomputer. C8051F series microcontroller has 7 kinds of products, selection of more than 500 varieties. Due to the highly integrated and the small package, C8051F MCU families have been widely used in the consumption, automobile, and communication market with limited space, low power consumption and low cost industries and so on [9-11].

\section{SELECTION FROM C8051F MCU FAMILY}

Due to the highly integrated and the small package, C8051F MCUs have been widely used in the consumption, automobile, and communication market with limited space, low power consumption and low cost industries and so on. C8051F MCU families have 7 kinds of products, with selection of more than 500 varieties, as shown in table 1 . In the actual teaching and learning process, there are a variety of selection from the C8051F MCU families according to different professional, different interests and hobbies, and the needs of type selection for learning and development.

TABLE I. APPLICATION FAMILIES OF C8051MCUS

\begin{tabular}{|c|c|c|c|c|}
\hline Application & Part Numbers & $\begin{array}{c}\text { Flash } \\
\text { (KB) }\end{array}$ & MIPS & $\begin{array}{l}\text { RAM } \\
\text { (KB) }\end{array}$ \\
\hline Capacitive touch sensing & C8051F7xx, C8051F8xx, C8051F99x & $4-32$ & 25 & $0.25-8$ \\
\hline Precision mixed-signal & $\begin{array}{l}\mathrm{C} 8051 \mathrm{~F} 00 \mathrm{x} / 1 \mathrm{x} / 2 \mathrm{x} / 4 \mathrm{x} / 6 \mathrm{x} \\
\mathrm{C} 8051 \mathrm{~F} 12 \mathrm{x} / 3 \mathrm{x}, \mathrm{C} 8051 \mathrm{~F} 35 \mathrm{x} / 7 \mathrm{x} / 9 \mathrm{x}\end{array}$ & $8-128$ & $20-100$ & $0.25-8.25$ \\
\hline Automotive and industrial & $\begin{array}{ll}\mathrm{C} 8051 \mathrm{~F} 85 \mathrm{x} / 6 \mathrm{x} & \mathrm{C} 8051 \mathrm{~F} 5 \mathrm{xx}, \\
\mathrm{C} 8051 \mathrm{~F} 12 \mathrm{x} / 3 \mathrm{x} & \\
\end{array}$ & $2-128$ & $25-50$ & $0.25-8$ \\
\hline Handheld devices \&sensor & $\begin{array}{l}\text { C8051F85x/6x, C8051F2xx } \\
\text { C8051F30x/1x/3x/6x/7x/9x } \\
\text { C8051F41x }\end{array}$ & $2-32$ & $25-100$ & $0.25-2.25$ \\
\hline USB & $\mathrm{C} 8051 \mathrm{~F} 32 \mathrm{x} / 4 \mathrm{x} / 8 \mathrm{x}$ & $16-64$ & 48 & $1.25-4.25$ \\
\hline CAN & $\mathrm{C} 8051 \mathrm{~F} 04 \mathrm{x} / 6 \mathrm{x}$ & $32-64$ & 25 & 4.25 \\
\hline Low-cost applications & C8051T60x/1x/3x & 2-16 OTP or EPROM & 25 & $0.25-1.25$ \\
\hline Ultra-low voltage \& power & $\begin{array}{l}\mathrm{C} 8051 \mathrm{~F} 90 \mathrm{x} / 1 \mathrm{x} / 2 \mathrm{x} / 3 \mathrm{x} \\
\mathrm{C} 8051 \mathrm{~F} 96 \mathrm{x} / 8 \mathrm{x} / 9 \mathrm{x}\end{array}$ & $2-128$ & 25 & $0.5-8.25$ \\
\hline
\end{tabular}

\section{EXPERIMENTAL METHODS AND MEANS}

The special development board, experiment box and simulation software were often employed in experimental for the traditional MCS-51 MCUs. Software programming was often later than hardware designing and debugging. The Initial software programming was debugging for only pure logic and computing. While with the increase of clock frequency and the complexity of packaging, this model is becoming more and more difficult for practical development.

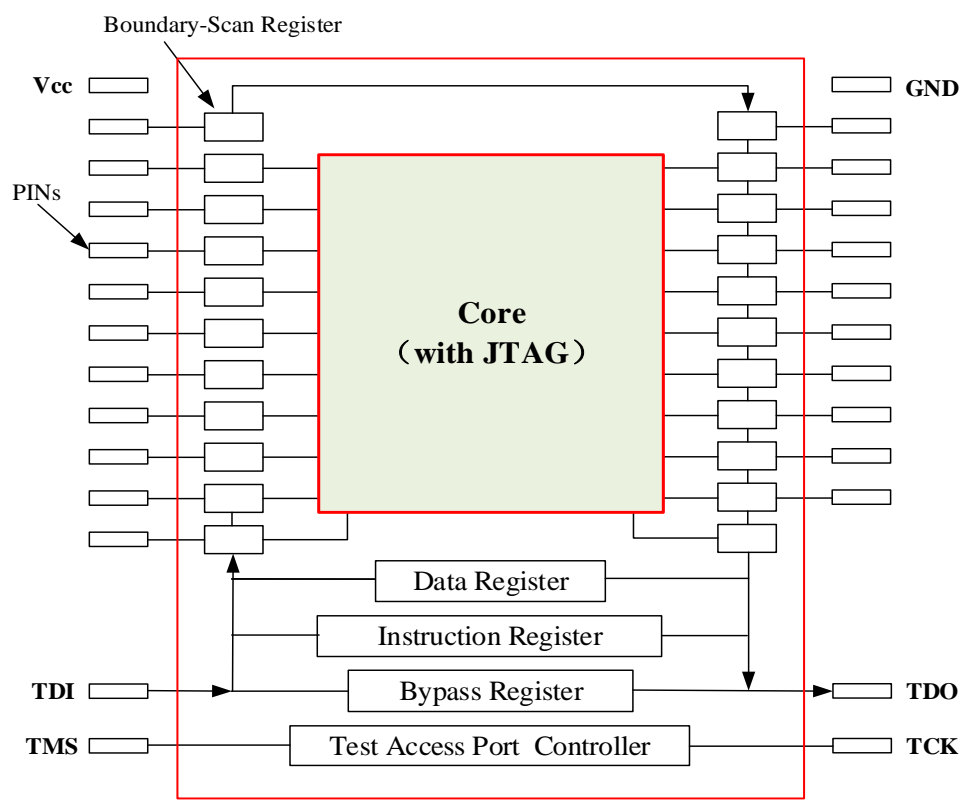

Fig. 1. Tructure of JTAG

The C8051F MCUs have on-chip JTAG (Joint European Test Action Group, JETAG) boundary scan and debug circuit that provides non-intrusive, full speed, in-circuit debugging using the production part installed in the end application, via the four-pin JTAG interface. The JTAG port is fully compliant to IEEE 1149.1, providing full boundary scan for test and manufacturing 
purposes without additional target RAM, program memory, timers, or communications channels. The debugging system supports inspection and modification of memory and registers, breakpoints, watch points, a stack monitor, and single stepping. All the digital and analog peripherals are functional and work correctly while debugging. All the peripherals (except for the ADC and SMBus) are stalled when the MCU is halted, during single stepping, or at a breakpoint in order to keep they synchronized.

The standard JTAG interface is accessed via four dedicated pins on the MCU: TCK, TMS, TDI, and TDO, respectively, mode selection, clock, data input and data output line. The debugging system requires a Windows 95/98/NT/ME/2000 computer with one available RS-232 serial port. The PC is connected via RS-232 to the Serial Adapter. A six-inch ribbon cable connects the Serial Adapter to the user's application board, picking up the four JTAG pins and VDD and GND. The Serial Adapter takes its power from the application board; it requires roughly $20 \mathrm{~mA}$ at 2.7-3.6 V. For applications where there is not sufficient power available from the target system, the provided power supply can be connected directly to the Serial Adapter. The structure of JTAG is shown in Fig. 1.

Through the 16-bit JTAG Instruction Register (IR), any of the seven instructions shown in Fig. 3 can be commanded. There are three DR's associated with JTAG Boundary-Scan, and four associated with Flash read/write operations on the C8051F MCUs. The DR in the Boundary Scan path is a 134-bit shift register. The Boundary DR provides control and observability of all the device pins as well as the SFR bus.

\section{REFORM OF TEACHING METHODS}

One of the key factors on learning a course well is students' interest always lacking for the hard course. Many students think that "hardware is difficult to learn", "learning is useless" and so on. The views have its complicated reasons in many aspects, such as characteristics of the hardware curriculum, more details of hardware, the working principle of the hardware and the way of thinking and behavior of "misfits", etc., so that students are not suited to the complex instructions and complex hardware circuit.

\section{A. Experimental Teaching}

For hardware courses, students should integrate theoretical knowledge with the actual computer, integrated circuit chip and so on, and deepen understanding and digest through carrying out the actual design and production. Because of the various restrictions of which are weak and confined with limited experimental courses, it is difficult for the students to solve the actual hardware design. For students' learning ability is uneven, so that many students regard computer hardware, such a "visible" and "touch" of things, but as "abstract" theory.

"Task driven" is an experimental teaching mode of inquiry teaching. Its remarkable feature is that both teaching and learning are based on several tasks in order to train students' ability of analyzing and solving problems themselves. Combinations thought of the "task driven" and computer hardware teaching, a new type of teaching content would be constructed by decomposing the theoretical knowledge and practical skills according into a few experimental subjects from the shallower to the deeper application with a clear goal. While the students complete these task independently within the specified time, so as to achieve the teaching goal.

\section{B. Quantitative Evaluation}

The traditional curriculum evaluation is confined to the final examination after the end of the course. For C8051F MCU family has many kinds, complex structure, abundant internal resources and so on, it is difficult to reflect the students' practical ability and scientific research innovation ability by traditional closed examination. Therefore, a new type of quantitative assessment mechanism for classroom assessment was proposed to evaluate the achievement abilities of students, according to the attendance, examination, scientific and technological innovation indicators, as shown in table 2.

TABLE II. QUANTITATIVE EVALUATION OF COURSE

\begin{tabular}{|l|l|c|c|}
\hline \multicolumn{1}{|c|}{ Contents } & \multicolumn{1}{|c|}{ Quantitative parameter } & Score (\%) & note \\
\hline Attendance & Attendance \& seating arrangement & 10 & 10 \\
\hline Performance & Discipline, answer the question and class participation. & $10 \%$ & $\leq 10 \%$ \\
\hline Homework & Homework assessment & 30 & $\leq 10 \%$ \\
\hline Examination & Final examination \& Mid-semester & $40 \%$ \\
\hline Experiment \& Innovation & $\begin{array}{l}\text { Confirmatory experiments, innovative design, related } \\
\text { competitions, scientific and technological innovations, } \\
\text { awards, etc. }\end{array}$ & & 100 \\
(up to 80\%) & \\
\hline Total & Comprehensive evaluation & & 100 \\
\hline
\end{tabular}

VI. SUMMARY

This paper reformed the teaching content of the course of the principle and application of single chip microcomputer in view of the current situation of the teaching and application based on C8051F Series MCU. First of all, the characteristics and applications of C8051F MCUs were analyzed. Then, the teaching methods were discussed by decomposing the theoretical knowledge and practical skills according into a few experimental subjects from the shallower to the deeper application with a clear goal. At last, a 
novel quantitative evaluation for students' learning achievement was also produced combined with the actual situation, quantitative assessment, comprehensive evaluation, etc. It is proved that the methods had great popularization and application value for training high-quality applied and professional talents.

\section{ACKNOWLEDGEMENT}

The Research was partially supported by "The reform and Practice Research of computer hardware basic course system of Applied Undergraduate Course" of the Research project on teaching reform of Shandong Provincial Education Department, China (NO. LU JIAO GAO WEN 2015-12), the science and technology development fund of Tai' an (No. 20133011, 201320629 and 2016GX0004), and the Foundation provided by Taishan University (no.Y-01-2013010). The authors also thank the associate editor and the anonymous reviewers for their valuable comments.

\section{REFERENCES}

[1] SANG Sheng-ju \& SHEN Ding. Principle and application of microcontroller. Beijing: China Railway Publishing House, 2010:2-10. (In Chinese)

[2] BAO Ke-jin. Principle and application of C8051F microcontroller. Beijing: China Electric Power Press, 2006:11-16. (In Chinese)

[3] YU Xiaoping, TANG Yingqiang, LI Shiwei. Design of On-chip Debug Unit Based on C8051.ELECTRONICS \& PACKAGING, 2017, 17(03):19-21+25. (In Chinese)

[4] SongYue,Yu Chiye, Hu Shen. Design and construction of SCM and Interface Technology excellent resource sharing course. Experimental Technology and Management, 2017,34(6):150-153. (In Chinese)

[5] ZHAO Nian-qiang, BAO Ke-jin. Education Reform of Principle and Application of Microcontroller Based on C8051F.Computer Education, 2010,(13):5760. (In Chinese)

[6] ZHANG Dong. Explore the way of developing 8 bit microcontroller from Cygnal C8051F. INFORMATION TECHNOLOGY, 2013,(04):123. (In Chinese)

[7] HE LI-min. Explore the way of developing 8 bit microcontroller from Cygnal C8051F. Microcomputer \& Embedded System,2002,(05):5-8. (In Chinese)

[8] SUN Li-xiang. Differences between Cygnal_C8051F020 and 80C51 MCU. TECHNOLOGICAL DEVELOPMENT OF ENTERPRISE, $2010,29(19): 63-65$.

[9] Information on http://www.silabs.com/products/mcu .Silicon Laboratories, Inc.

[10] Information on https://en.wikipedia.org/wiki/Category: Microcontrollers

[11] Information on http://www.silabs.com/products/mcu/8-bit. Silicon Laboratories, Inc. - 8-bit Microcontroller Studio, Individual Components 